\title{
The Unholy Alliance between Obesity, Type-2 Diabetes, the Sympathetic Nervous System, and Hypertension in Young/Middle-Aged Subjects
}

\section{JM Cruickshank*}

Independent Cardiovascular Consultant, Long Melford, Great Britain, UK

\begin{abstract}
There is an obesity/type-2 diabetes (DM2)/hypertension epidemic in developed countries around the world. The purpose of this review is to examine the interrelationships between obesity, DM2 and hypertension in young/middleaged subjects, highlighting the importance of raised sympathetic nerve activity and treatment implications.

Central obesity is associated with insulin-resistance, and high plasma insulin and leptin levels. Insulin and leptin act upon the mid-brain, resulting in increased sympathetic nerve activity and blood pressure. Chronically raised sympathetic nerve activity, independent of blood pressure, is a powerful predictor of myocardial infarction in the middle-aged.

Weight-loss, via life-style change or bariatric surgery, results in blood pressure reduction. Anti-hypertensive agents that increase sympathetic nerve activity, e.g. diuretics, dihydropyridine calcium antagonists, and angiotensin receptor blockers (ARBs), do not reduce (and may increase) the risk of myocardial infarction in younger/middleaged subjects with hypertension and DM2. Beta-1 blockade, which is effective in regressing and stabilising coronary atheromataous plaque, is preferable to ACE-inhibition, and is the first-line treatment of choice.
\end{abstract}

\section{Introduction}

Since 1980 there has been a marked global increase in body mass index (BMI) [1]. The nine countries of Oceania have the highest BMI in the world, being (on average) $35.0 \mathrm{~kg} / \mathrm{m}^{2}$ for women, and $33.9 \mathrm{~kg} / \mathrm{m}^{2}$ for men [1]: the lowest BMIs occur in Bangladesh and in sub-Saharan Africa [1]

The highest BMIs within developed countries are in the USA, where $66 \%$ of adults are overweight / obese (BMI $>25 \mathrm{~kg} / \mathrm{m}^{2}[1,2]$. The UK and Australasia are not far behind (the USA), where about $60 \%$ of the adult population are overweight/obese [3,4]. Undoubtedly the low price of fast-food is a vital factor. Interestingly, in high-income countries, obesity affects mainly middle-aged adults from disadvantaged groups, in contrast to low-income countries where obesity is prevalent in individuals from wealthy urban environments [5]. However, as a general rule, obesity is less prevalent among highly educated wealthy individuals [2].

Obesity is clearly related to excessive calorie-intake. Equally important is calorie output. A genetic predisposition to obesity is exacerbated by a sedentary lifestyle involving minimal physical activity and an excess of television watching [6].

Weight gain during middle-age is associated with an increased risk of type-2 diabetes (DM2) [7]. Central obesity is the main problem and according to the WHO is responsible for $44 \%$ of DM2 [2]. During times of economic crisis (Cuba) the frequency of DM2 declined markedly, in contrast to better economic times when the frequency of DM2 increased [8].

DM2 is associated with a twofold increase in cardiovascular events [9]. The frequency of DM2 is predicted to rise steeply until 2030, giving rise to marked increases in the risk of heart disease, stroke and cancer [10]. Such events will inevitably result in marked economic consequences $[10,11]$.

England has a major obesity problem with children, with about one third of 10-11 year olds being overweight/obese [3]. In the UK, a study in pre-pubertal children revealed that $13 \%$ of boys and $18 \%$ of girls are overweight, and $5.3 \%$ of boys and $5.0 \%$ of girls are obese
[12]. A similar situation pertains in the USA [13]. Childhood obesity tracks into adulthood, being particularly severe in non-Hispanic black women [14]. A high BMI in adolescence is associated with the early appearance of DM2 in adulthood [15].

This review sets out to examine the interrelationships between obesity, type- 2 diabetes, and essential hypertension, and to highlight the importance of raised sympathetic nerve activity and treatment implications.

\section{Obesity and Essential Hypertension}

Although genetic factors account for about $30 \%$ of cases of essential hypertension, lifestyle factors such as overweight/obesity, physical inactivity, high salt intake, alcohol abuse, and a typical western diet, account for the remaining $70 \%[16,17]$.

The classic Framingham study showed that in an initially healthy population a) the development of diastolic ( \pm systolic) hypertension occurred in the young/middle-aged, and was closely linked to overweight/obesity, b) the development of isolated systolic hypertension occurred in the elderly, and was a function of aging/ stiffening of the arteries (Table 1) [18].

Others have confirmed the association between obesity and essential hypertension in the young/middle-aged, and that central obesity was the important component [19-22]. A study involving

*Corresponding author: JM Cruickshank, DM (Oxford), FRCP (London) Independent Cardiovascular Consultant, Long Melford, Great Britain, UK, Tel: +44 01787 310803; E-mail: johndt!@aol.com

Received November 21, 2013; Accepted January 20, 2014; Published January 23, 2014

Citation: Cruickshank JM (2014) The Unholy Alliance between Obesity, Type-2 Diabetes, the Sympathetic Nervous System, and Hypertension in Young/MiddleAged Subjects. J Mol Genet Med S1: 016. doi: 10.4172/1747-0862.S1-016

Copyright: (C) 2014 Cruickshank JM. This is an open-access article distributed under the terms of the Creative Commons Attribution License, which permits unrestricted use, distribution, and reproduction in any medium, provided the original author and source are credited 
Citation: Cruickshank JM (2014) The Unholy Alliance between Obesity, Type-2 Diabetes, the Sympathetic Nervous System, and Hypertension in Young/Middle-Aged Subjects. J Mol Genet Med S1: 016. doi: 10.4172/1747-0862.S1-016

Page 2 of 7

\begin{tabular}{|c|c|}
\hline $\begin{array}{l}\text { Predictors of Diastolic Hypertension }( \pm \\
\text { Systolic Hypertension })=\mathrm{DBP}^{3} 90 \mathrm{mmHg} \\
\left( \pm \mathrm{SBP}^{3} 140 \mathrm{mmHg}\right)\end{array}$ & $\begin{array}{c}\text { Predictors of Isolated Systolic } \\
\text { Hypertension }=\mathrm{SBP}^{3} 140 \mathrm{mmHg}+\mathrm{DBP} \\
<90 \mathrm{mmHg} \text { (wide P-P) }\end{array}$ \\
\hline 1. Young age & 1. Older age \\
\hline 2. Male sex & 2. Female sex \\
\hline 3. High BMI at baseline & $\begin{array}{l}\text { 3. Increased BMI during follow-up } \\
\text { (weak) }\end{array}$ \\
\hline 4. Increased BMI during follow-up & $\begin{array}{l}\text { 4. ISH arises more commonly from } \\
\text { normal and high normal BP, than } \\
\text { "burned out" diastolic hypertension }\end{array}$ \\
\hline \multirow[t]{2}{*}{$\begin{array}{l}\text { 5. Main mechanism of } \mathrm{DH} \text { and } \mathrm{SDH} \text { is } \\
\text { raised peripheral resistance }\end{array}$} & $\begin{array}{l}\text { 5. Only } 18 \% \text { with new - onset ISH had } \\
\text { a previous } \mathrm{DBP}^{3} 95 \mathrm{mmHg}\end{array}$ \\
\hline & $\begin{array}{l}\text { 6. Main mechanism of ISH is increased } \\
\text { arterial stiffness=aging of arteries }\end{array}$ \\
\hline
\end{tabular}

Table 1: Different predictors of diastolic and isolated systolic hypertension. The Framingham Group, Circulation 2005

young, white men, with a 46 year follow-up, confirmed the obesity/ hypertension link, but that weight-loss when young prevented the later onset of hypertension [23].

A study in 6,576 children aged 10-11 years demonstrated a strong link between obesity and raised blood pressure [24]. A study of children aged 8-17 years found that a blood pressure greater than $120 / 80 \mathrm{~mm} \mathrm{Hg}$ was found in $16-19 \%$ of boys and $8-13 \%$ of girls, and that high blood pressure was closely related to a high BMI and waist circumference [25]. In boys, hypertension was related to high levels of visceral fat, while in girls hypertension was related to a high total fat [26]. If obese teenagers achieve normal weight, there was no later increase in blood pressure [27]. Blood pressure control related to a decrease in waist circumference and visceral fat [28].

\section{Obesity, Diabetes, Hypertension and High Sympathetic Nerve Activity and Heart Rates}

Central obesity is linked not only to hypertension in the young/ middle-aged, but also to a high resting heart rate and cardiac output [22]. The Framingham Group have noted an association between hypertension and high heart rates in young/middle-aged subjects [29]. A high heart rate is likely to be a surrogate for high sympathetic nerve activity.

Obesity, particularly central, is linked to increased muscle sympathetic nerve activity [30] (Figure 1). In men there is a powerful positive linear relationship between waist circumference and sympathetic nerve activity [31]. Though in normal-weight, young/ middle-aged hypertensive subjects sympathetic nerve activity is raised [32], it is less than in age-matched obese hypertensive subjects [33]. It thus comes as no surprise that in patients with the metabolic syndrome or DM2 where central obesity is very common, there is a marked increase in sympathetic nerve activity, particularly when hypertension is also present $[34,35]$. Increased sympathetic nerve activity, as expressed by increased arterial norepinephrine (noradrenaline), is significantly greater in cases of DM2 than the metabolic syndrome (presumably a reflection of a greater degree of central obesity and higher plasma insulin and leptin levels in the former - see later) [36].

Although invasive studies of sympathetic nerve activity have not been done in children, obese hypertensive children and adolescents have higher resting heart rates and blood pressure variability than lean hypertensive controls $[24,37]$.

Brown adipose tissue is present in small amounts in children and adults, and is involved in the process of thermogenesis ie calories are burnt to produce heat [38]. Brown fat activity in adult humans correlates inversely with BMI [39]. High brown fat activity is closely linked to high sympathetic nerve activity [40].

\section{The Link between Central Obesity and Increased Sympathetic Nerve Activity}

The likely series of events linking central obesity with high sympathetic nerve activity and hypertension have been described by the author [41]. Briefly, centrally located adipocytes produce several vasculotoxic adipokines and cytokines e.g. tumor necrosis factor (TNF-alpha) and interleukin-6 (IL-6), which act upon the liver, resulting in release of C-reactive protein (CRP), an indicator of acute inflammation. Endothelial/hepatic inflammation leads to an insulinresistant state, resulting in increased insulin secretion. High insulin levels, in addition to high leptin levels (produced mainly by central adipocytes), act upon the hypothalamic region of the brain resulting in increased sympathetic outflow and renin release (via beta-1 stimulation of the renal juxta -glomerular apparatus). High renin levels result in angiotensin II production, which (like leptin and insulin) acts centrally, resulting in increased sympathetic outflow.

The whole process is illustrated in Figure 2, which also indicates the results of chronic beta- 1 stimulation upon the periphery and the theoretical benefits of beta-1 blockade. It is of interest to note that in obesity-related hypertension, antagonists of insulin and particularly of leptin, administered intra-cerebrally, result in a reduction of both renal sympathetic nerve activity and blood pressure [42].

\section{Obesity and Premature Mortality}

In white adults, overweight and obesity (and possibly underweight)

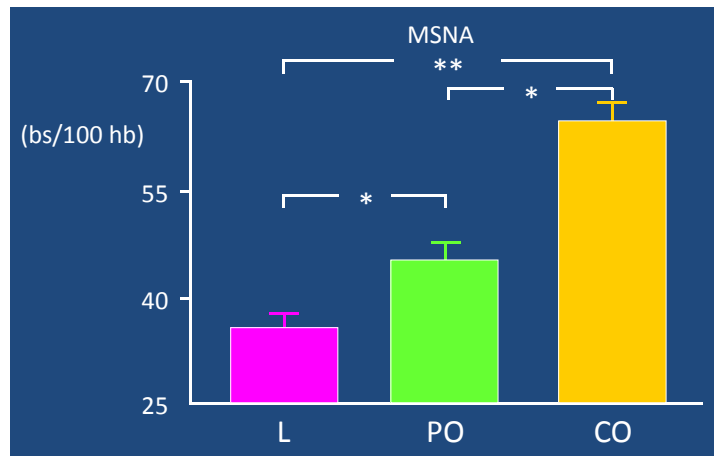

Figure 1: Muscle sympathetic nerve activity (MSNA) is highest with central obesity (CO) than with peripheral obesity (PO) and leanness (L) (mean age 36 years) [32]

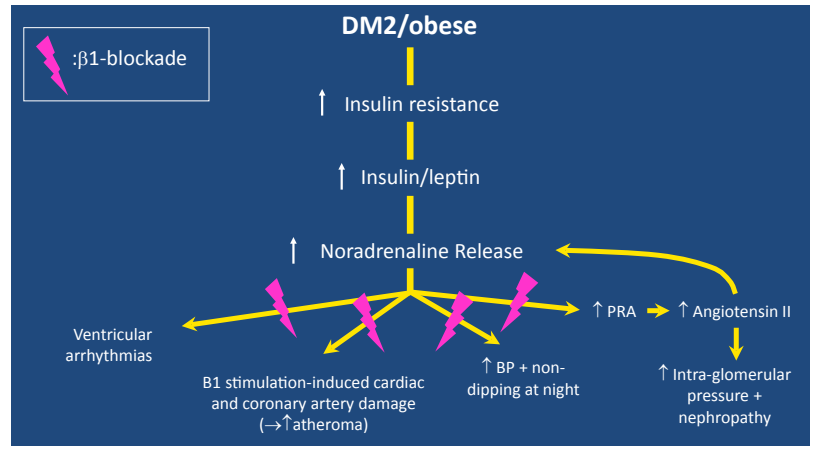

Figure 2: Beta-1 blockade is beneficial in central obesity/insulin resistance/DM2 plus hypertension (high sympathetic nerve activity) [43] 
Citation: Cruickshank JM (2014) The Unholy Alliance between Obesity, Type-2 Diabetes, the Sympathetic Nervous System, and Hypertension in Young/Middle-Aged Subjects. J Mol Genet Med S1: 016. doi: 10.4172/1747-0862.S1-016

are associated with increased all-cause mortality [43]. The relationship was U-shaped, with an optimal BMI being 20-25. A similar relationship exists for Asian countries, excepting India and Bangladesh [44]. In the black community there was a similar U-shaped relationship between BMI and all-cause death, and for central obesity in those with a normal BMI, in women only [45].

In young adults, a high BMI increased the risk of early DM2 and later coronary heart disease as well as coronary artery calcification in middle-age $[15,46]$.

Several publications have shown BMI to be inversely associated with mortality in patients with coronary artery disease - the socalled "obesity paradox" [47,48]. More recent information suggests that overweight subjects with coronary artery disease have the best prognosis, while severe obesity is linked to the worst prognosis [48]. It has been suggested that the worst prognosis for patients with coronary artery disease is associated with normal weight with central obesity [49].

\section{Increased Sympathetic Nerve Activity, and High Resting Heart Rates, are Predictors of Premature Death and Cardiovascular Events}

\section{Resting heart rates}

High resting heart rates (a possible surrogate for sympathetic nerve activity) are closely linked to increased risk of all-cause death and coronary heart disease [50,51]. In middle-aged hypertensive subjects in the Framingham Study followed-up for 36 years, high resting heart rates, particularly over $85 \mathrm{bpm}$, were closely related to increased rates of all-cause death, and cardiovascular and coronary artery disease events, in both men and women [52]. It is worth noting that in men, high heart rates increase the risk of rupture of unstable coronary atheromatous plaque [53].

\section{Sympathetic nervous system}

Chronic sympathetic nerve over-activity can lead to adverse cardiovascular consequences, possibly via reduced diastolic fillingtime, increased cardiac oxygen requirement, reduced threshold for ventricular arrhythmias, and induced cardiac apoptosis/necrosis $[41,54]$.

In a normal population, plasma norepinephrine levels peak at early/mid-morning (the "waking response"), and this event coincides with a peaking of the risk of both myocardial infarction and sudden death (the "vulnerable period") [55]. In patients with chronic ischemia, ischemic episodes (ECG) peak at the time of rising from bed [56].

Of particular relevance is a study in young/middle-aged hypertensive subjects followed-up for $6-7$ years, where relationships between different levels of plasma norepinephrine and epinephrine, beta-receptor density and cardiovascular events were studied [57]. High plasma norepinephrine levels were strongly linked to a high risk of both all-cause death and cardiovascular mortality, independent of blood pressure. In that same study there was a strong positive relationship, again independent of blood pressure, between lymphocyte betareceptor density (Bmax) and cAMP levels, and myocardial infarction (but not stroke) (Figure 4). It is thus apparent that in younger/ middle-aged hypertensive subjects (with or without DM2), the risk of myocardial infarction is linked to sympathetic nerve activity, and the risk of stroke to the level of blood pressure.

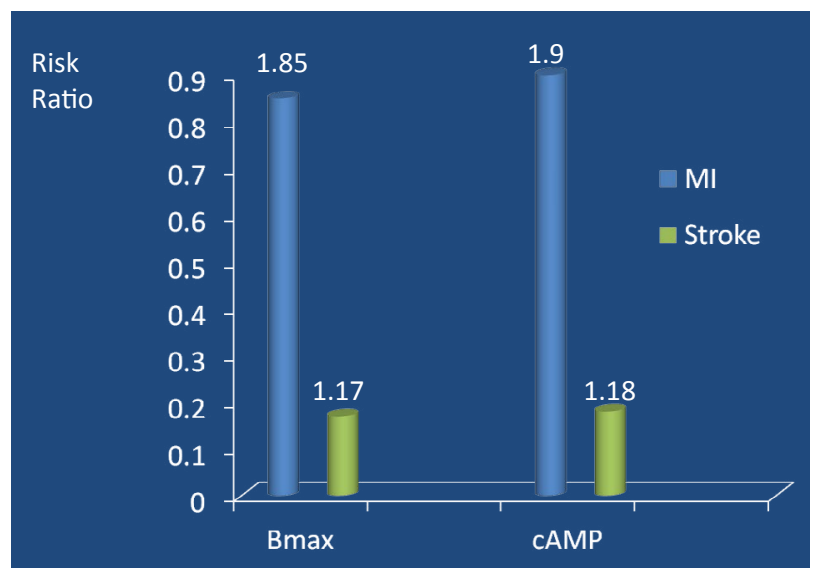

Figure 3: Beta-receptor density (Bmax) and cAMP (lymphocytes) as predictors of myocardial infarction (but not stroke) in middle-aged hypertensive subjects followed for 7 years [60].

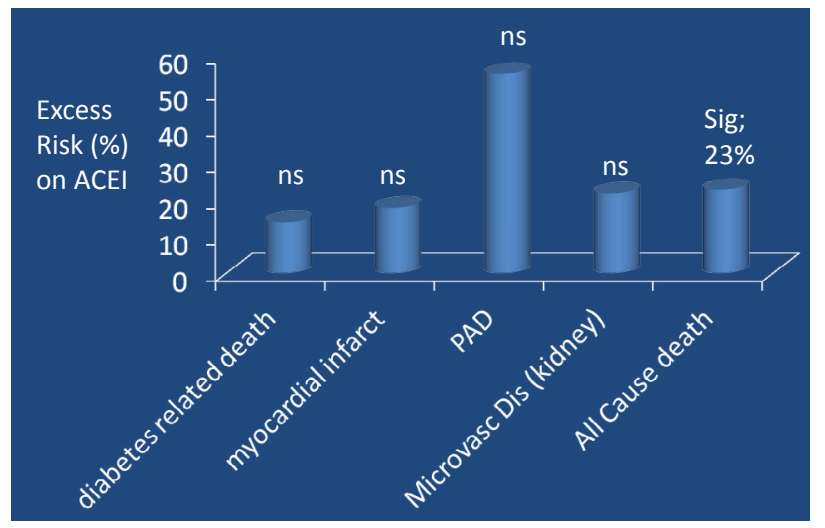

Figure 4: UKPDS 20 year follow-up; excess risk (significant for all-cause death) in group initially randomised to ACEI (vs beta-blocker) [70].

\section{Appropriate Treatment for the Young/Middle-Aged, Overweight/Obese Type-2 Diabetic with Hypertension}

\section{Lifestyle, bariatric surgery, and renal artery denervation}

The mainstay of obesity treatment remains lifestyle modification aimed at reducing calorie intake and increasing physical activity [58]. However, treating obesity via prolonged lifestyle modification has proved disappointing, particularly among children who often find television, computers and smart phones more attractive than a game of football or a cycle ride.

However, public health approaches hold promise for reducing obesity at a population level [58]. There is clearly an important role for government in reducing excess calorie consumption, supporting regulation of certain products, and encouraging food companies to voluntarily produce and market more healthy foods.

Bariatric surgery can be remarkably successful in inducing remission of DM2 in obese patients [59]. Not only is the diabetic situation improved, but antihypertensive therapy is required less often [60]. A recent overview has indicated that 5-7 years post-bariatric surgery, there was a $66 \%$ improvement in remission of hypertension [61]. In an ongoing non-randomised comparative study, bariatric 
Citation: Cruickshank JM (2014) The Unholy Alliance between Obesity, Type-2 Diabetes, the Sympathetic Nervous System, and Hypertension in Young/Middle-Aged Subjects. J Mol Genet Med S1: 016. doi: 10.4172/1747-0862.S1-016

Page 4 of 7

surgery was significantly more effective than usual-care in reducing the risk of cardiovascular events and death [62].

Type-2 diabetics are particularly prone to resistant hypertension i.e. a high blood pressure that remains uncontrolled in spite of receiving at least 3 different classes of antihypertensive agent (one being a diuretic) [63]. Such cases respond well to renal sympathetic denervation [64].

\section{Antihypertensive drug therapy and cardiovascular endpoints}

As high resting heart rates and increased plasma norepinephrine and lymphocyte beta-receptor density/cyclic AMP levels predict future myocardial infarctions in young/middle-aged hypertensive subjects (independent of blood pressure) (Figure 3), one might predict a particular benefit from beta-1 blockade (Figure 2) [52,55,57]. Equally, one might predict an absence of protection (from myocardial infarction) in younger patients from antihypertensive agents that increase sympathetic nerve activity i.e. dihydropyridine calcium blockers, diuretics, and angiotensin receptor blockers (ARBs).

Beta-blockers: There is only one study involving beta-blockers in younger/middle-aged hypertensive subjects with DM2, and that is UKPDS $[65,66]$. These patients were overweight/obese (mean BMI $30 \mathrm{~kg} / \mathrm{m} 2$ ), and were randomised to tight or less-tight control of blood pressure [65]. After 8 - 9 year follow-up, it was clear that in the tightcontrol group there were significant benefits in reducing the 7 primary end-points. Within the tight-control group there was a randomised comparison between atenolol and captopril [65]. When examining the effects of these 2 agents versus less-tight control, it was evident that the trends in reducing the frequency of all 7 primary end-points (any diabetes end-point, diabetes mortality, all-cause mortality, myocardial infarction, stroke, peripheral arterial disease, and microvascular disease (eye and kidney) favoured atenolol (including heart failure risk reduction, which was a secondary end-point). Notable was that atenolol (vs less-tight control) a) reduced stroke-risk by $50 \%$ (thus confounding the notion that beta-blockers perform poorly in this area) b) reduced microvascular end-points by $45 \%$ (again confounding the notion that ACE-inhibitors have special reno-protective properties) c) reduced peripheral arterial disease end-points by $60 \%$ (thus denying the idea that beta-blockers and peripheral arterial disease are "poor bed-fellows" d) reduced the risk of heart failure by $60 \%$. All of the benefits observed in the atenolol-group were in spite of a $1.8 \mathrm{~kg}$ increase in weight, and an increase in glycated haemoglobin concentrations.

There was a 20 year follow-up in UKPDS (Figure 4) [67]. The trends favouring atenolol (vs captopril) remained, but now there was a significant $23 \%$ excess in all-cause death in the ACE-inhibitor group. Thus, beta-blockade appears preferable to ACE-inhibition in the treatment of young/middle-aged hypertensive subjects with DM2.

Dihydropyridine calcium antagonists: The ABCD Study involving middle-aged hypertensive subjects with DM2, compared the effects of nisoldipine with enalapril, and was stopped prematurely [68]. The reason for the premature cessation of the study was a significant excess of cases of myocardial infarction in the calcium antagonist group - 25vs 5 , in spite of similar falls in blood pressure in the 2 groups. Of likely relevance is the fact that dihydropyridine calcium antagonists increase both resting heart rate and plasma norepinephrine concentrations [69].

In a study involving middle-aged patients with diabetic nephropathy and hypertension, randomised to placebo, or amlodipine, or the angiotensin receptor blocker irbesartan, there was no difference in the composite end-point event-rate between the 3 randomised treatments [70].

ACE-inhibitors (ACE-I): As already mentioned, in the UKPDS study involving obese hypertensive subjects with DM2, the reduction in the 7 primary end-points (vs less-tight control of blood pressure) was similar in the ACE-I and beta-blocker groups (though all 7 trends favoured the beta-blocker atenolol vs captopril) [65,66]. At 20 years follow-up, there was a significant $23 \%$ reduction in the risk of all-cause death in those initially randomised to atenolol (Figure 4) [67].

Angiotensin receptor blockers (ARBs): There are 2 randomised, hard endpoint, placebo-controlled trials in middle-aged type-2 diabetics involving the ARB olmesartan. One study included diabetic patients with nephropathy and high blood pressure, and there was an excess (10 vs 3 ) of cardiovascular deaths in the olmesartan group [71]. The other study, the so-called ROADMAP Study involved type-2 diabetics with pre-hypertension [72]. Although the ARB delayed the onset of microalbuminuria, there was in the ARB group a significant excess of cardiovascular deaths, particularly in those with a history of coronary heart disease, in addition to an excess of the risk of sudden death and death due to myocardial infarction (Figure 5).

Noteworthy is the fact that (unlike ACEIs) ARBs increase sympathetic nerve activity in young/middle-aged subjects [73,74]. As already indicated in a study involving middle-aged patients with diabetic nephropathy and hypertension, there was no difference in the

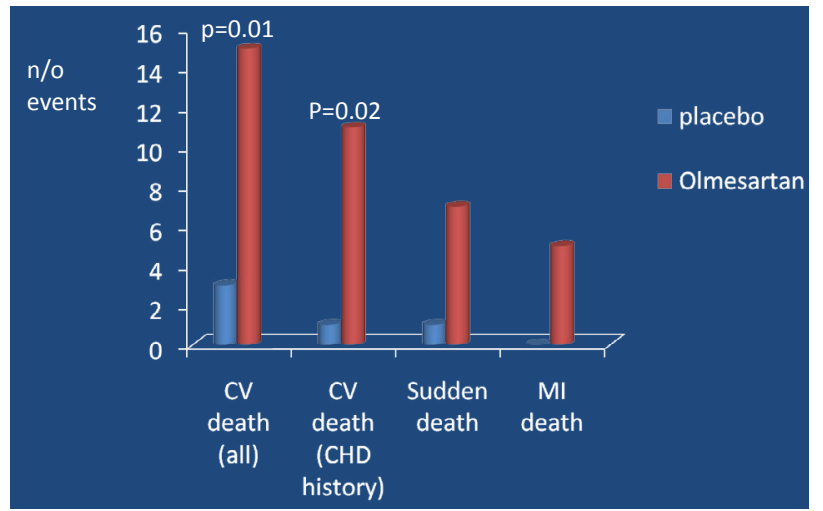

Figure 5: ROADMAP Study; excess cardiovascular events in those randomised to ARB olmesartan (vs placebo) [75]

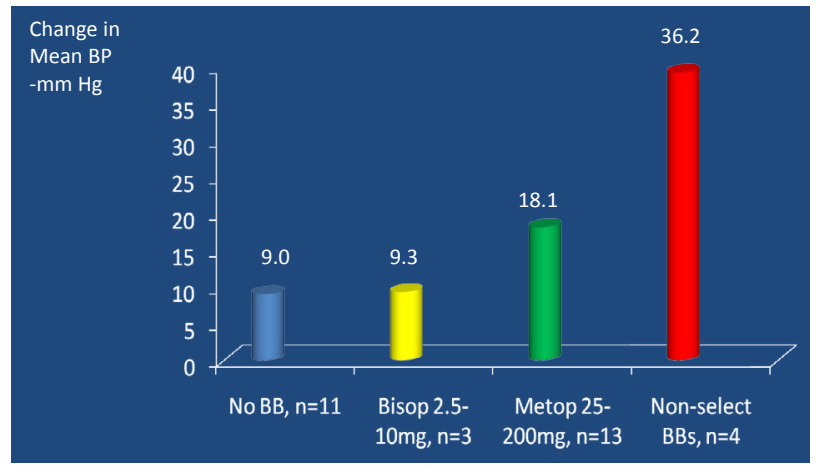

Figure 6: Perioperative interaction (change in blood pressure) between epinephrine and various beta-blockers. 
Citation: Cruickshank JM (2014) The Unholy Alliance between Obesity, Type-2 Diabetes, the Sympathetic Nervous System, and Hypertension in Young/Middle-Aged Subjects. J Mol Genet Med S1: 016. doi: 10.4172/1747-0862.S1-016

composite endpoint event-rate in those randomised to either placebo, amlodipine, or irbesartan [70].

Diuretics: There are no studies involving diuretic therapy in young/middle-aged hypertensive subjects with DM2. However, there are 3 studies in this age-group, incorporating hypertensive subjects without DM2, involving thiazide-type diuretics [75-77]. In all 3 studies, compared to randomised placebo/non-treatment, there was a significant reduction in the risk of stroke, but no reduction in the risk of myocardial infarction in the diuretic group; indeed in one study there was a significant increase in the risk of myocardial infarction [77].

Undoubtedly relevant regarding these worrying results is the fact that thiazide-like diuretics, in contrast to spironolactone, increase sympathetic nerve activity [78].

\section{Beta-Blockers (Beta-1 Blockade) are the Preferred Antihypertensive agents in Young/Middle-Aged Hypertensive Subjects with Type-2 Diabetes}

Pure beta-2 blockade (ICI 118,551) results in an increase in blood pressure of about $7 / 5 \mathrm{~mm} \mathrm{Hg}$ [41]. Thus, non-selective propranolol is less effective than moderately beta-1 selective atenolol in reducing blood pressure and atenolol, in turn, is less effective than highly beta-1 selective bisoprolol in reducing both peripheral (brachial) and central aortic pressures [41,79]. Indeed, bisoprolol is a more effective antihypertensive agent than randomised diuretic, calcium blocker, alpha blocker and ACE-inhibitor and ARBs in young/middle-aged hypertensive subjects; and is at least as reno-protective as an ARB [8082]. Bisoprolol is also at least as effective as ACE-inhibition in reducing left ventricular hypertrophy in younger hypertensive subjects [83].

High beta-1 selectivity will also reduce the chance of adverse reactions [41]. Thus, metabolic disturbance involving blood sugar, HbA1-c, insulin sensitivity, free fatty acids, plasma triglycerides, VLDL, and HDL, which are closely associated with beta- 2 blockade, can be avoided by using highly beta-1 selective agents [41].

The smoking interaction with non, or poorly, selective beta-blockers can be avoided by using highly beta-1 selective agents [41]. Nicotine stimulates release of epinephrine which in turn stimulates beta-1, beta2 , and alpha receptors [41]. In the presence of non, or poorly selective beta-blockers, uncontrolled alpha constriction can occur, resulting in increases in mean blood pressure (vs non-treatment) of $30 \mathrm{~mm} \mathrm{Hg}$ with non-selective agents, $9 \mathrm{~mm} \mathrm{Hg}$ with moderately selective metoprolol, and no change with highly beta-1 selective bisoprolol (Figure 6) [84].

Are beta-blocker-induced metabolic changes dangerous? Probably not, as witnessed by the excellent performance of atenolol in the UKPDS study, in spite of increases in plasma Hb A1-c (Figure 4) $[65,67]$. Undoubtedly important in the good long-term results with beta-blockers in young/middle-aged hypertensive subjects (at least in the non-smokers) is the fact that they have been shown to regress the coronary atheromataous process in middle-aged subjects and to stabilise the unstable coronary plaque $[41,53,85]$.

\section{References}

1. Lopez AD, Mathers CD, Ezzati M, Jamison DT, Murray CJ (2006) Global and regional burden of disease and risk factors, 2001: systematic analysis of population health data. Lancet 367: 1747-1757.

2. Finucane MM, Stevens GA, Cowan MJ, Danaei G, Lin JK, et al. (2011) National, regional, and global trends in body-mass index since 1980: systematic analysis of health examination surveys and epidemiological studies with 960 countryyears and 9.1 million participants. Lancet 377: 557-567.
3. [No authors listed] (2013) Obesity: many hands to make light(er) work. Lancet 381: 89

4. Dunstan DW, Zimmet PZ, Welborn TA, Cameron AJ, Shaw J, et al. (2002) The Australian Diabetes, Obesity and Lifestyle Study (AusDiab)--methods and response rates. Diabetes Res Clin Pract 57: 119-129.

5. Swinburn BA, Sacks G, Hall KD, McPherson K, Finegood DT, et al. (2011) The global obesity pandemic: shaped by global drivers and local environments. Lancet 378: 804-814.

6. Qi Q, Li Y, Chomistek AK, Kang JH, Curhan GC, et al. (2012) Television watching, leisure time physical activity, and the genetic predisposition in relation to body mass index in women and men. Circulation 126: 1821-1827.

7. Biggs ML, Mukamal KJ, Luchsinger JA, Ix JH, Carnethon MR, et al. (2010) Association between adiposity in midlife and older age and risk of diabetes in older adults. JAMA 303: 2504-2512.

8. Franco M, Bilal U, Orduñez P, Benet M, Morejón A, et al. (2013) Populationwide weight loss and regain in relation to diabetes burden and cardiovascula mortality in Cuba 1980-2010: repeated cross sectional surveys and ecological comparison of secular trends. BMJ 346: f1515.

9. Emerging Risk Factors Collaboration, Sarwar N, Gao P, Seshasai SR, Gobin $\mathrm{R}$, et al. (2010) Diabetes mellitus, fasting blood glucose concentration, and risk of vascular disease: a collaborative meta-analysis of 102 prospective studies. Lancet 375: 2215-2222.

10. Wang YC, McPherson K, Marsh T, Gortmaker SL, Brown M (2011) Health and economic burden of the projected obesity trends in the USA and the UK. Lancet 378: $815-825$

11. Gortmaker SL, Swinburn BA, Levy D, Carter R, Mabry PL, et al. (2011) Changing the future of obesity: science, policy, and action. Lancet 378: 838-847.

12. Falaschetti E, Hingorani AD, Jones A, Charakida M, Finer N, et al. (2010) Adiposity and cardiovascular risk factors in a large contemporary population of pre-pubertal children. Eur Heart J 31: 3063-3072.

13. Kelly AS, Barlow SE, Rao G, Inge TH, Hayman LL, et al. (2013) Severe obesity in children and adolescents: identification, associated health risks and treatment approaches. A scientific statement from the American Heart Association. Circulation 128: 1689-1712.

14. The NS, Suchindran C, North KE, Popkin BM, Gordon-Larsen P (2010) Association of adolescent obesity with risk of severe obesity in adulthood. JAMA 304: 2042-2047

15. Tirosh A, Shai I, Afek A, Dubnov-Raz G, Ayalon N, et al. (2011) Adolescent BM trajectory and risk of diabetes versus coronary disease. N Engl J Med 364 $1315-1325$.

16. Cowley AW Jr, Nadeau JH, Baccarelli A, Berecek K, Fornage M, et al. (2012) Report of the National Heart, Lung, and Blood Institute Working Group on epigenetics and hypertension. Hypertension 59: 899-905

17. Beilin LJ (2004) Hypertension research in the 21st century: where is the gold? J Hypertens 22: 2243-2251.

18. Franklin SS, Pio JR, Wong ND, Larson MG, Leip EP, et al. (2005) Predictors of new-onset diastolic and systolic hypertension: the Framingham Heart Study. Circulation 111: 1121-1127.

19. Toprak A, Wang H, Chen W, Paul T, Srinivasan S, et al. (2008) Relation of childhood risk factors to left ventricular hypertrophy (eccentric or concentric) in relatively young adulthood (from the Bogalusa Heart Study). Am J Cardio 101: $1621-1625$

20. Rhéaume C, Arsenault BJ, Bélanger S, Pérusse L, Tremblay A, et al. (2009) Low cardiorespiratory fitness levels and elevated blood pressure: what is the contribution of visceral adiposity? Hypertension 54: 91-97.

21. Timpson NJ, Harbord R, Davey Smith G, Zacho J, Tybjaerg-Hansen A, et al (2009) Does greater adiposity increase blood pressure and hypertension risk?: Mendelian randomization using the FTO/MC4R genotype. Hypertension 54 84-90

22. Drukteinis JS, Roman MJ, Fabsitz RR, Lee ET, Best LG, et al. (2007) Cardiac and systemic hemodynamic characteristics of hypertension and prehypertension in adolescents and young adults: the Strong Heart Study. Circulation 115: 221-227.

23. Shihab HM, Meoni LA, Chu AY, Wang NY, Ford DE, et al. (2012) Body mass 
Citation: Cruickshank JM (2014) The Unholy Alliance between Obesity, Type-2 Diabetes, the Sympathetic Nervous System, and Hypertension in Young/Middle-Aged Subjects. J Mol Genet Med S1: 016. doi: 10.4172/1747-0862.S1-016

Page 6 of 7

index and risk of incident hypertension over the life course: the Johns Hopkins Precursors Study. Circulation 126: 2983-2989.

24. Charakida M, Jones A, Falaschetti E, Khan T, Finer N, et al. (2012) Childhood obesity and vascular phenotypes: a population study. J Am Coll Cardiol 60: 2643-2650.

25. Rosner B, Cook NR, Daniels S, Falkner B (2013) Childhood blood pressure trends and risk factors for high blood pressure: the NHANES experience 19882008. Hypertension 62: 247-254.

26. Denton KM, Hilliard LM, Tare M (2013) Sex-related differences in hypertension: seek and ye shall find. Hypertension 62: 674-677.

27. Suglia SF, Clark CJ, Gary-Webb TL (2013) Adolescent obesity, change in weigh status, and hypertension: racial/ethnic variations. Hypertension 61: 290-295.

28. Niemirska A, Litwin M, Feber J, Jurkiewicz E (2013) Blood pressure rhythmicity and visceral fat in children with hypertension. Hypertension 62: 782-788.

29. Cheng S, Xanthakis V, Sullivan LM, Vasan RS (2012) Blood pressure tracking over the adult life course: patterns and correlates in the Framingham heart study. Hypertension 60: 1393-1399.

30. Grassi G, Dell'Oro R, Facchini A, Quarti Trevano F, Bolla GB, et al. (2004) Effect of central and peripheral body fat distribution on sympathetic and baroreflex function in obese normotensives. J Hypertens 22: 2363-2369.

31. Joyner MJ, Charkoudian N, Wallin BG (2010) Sympathetic nervous system and blood pressure in humans: individualized patterns of regulation and their implications. Hypertension 56: 10-16.

32. Schlaich MP, Lambert E, Kaye DM, Krozowski Z, Campbell DJ, et al. (2004) Sympathetic augmentation in hypertension: role of nerve firing, norepinephrine reuptake, and Angiotensin neuromodulation. Hypertension 43: 169-175.

33. Lambert E, Straznicky N, Schlaich M, Esler M, Dawood T, et al. (2007) Differing pattern of sympathoexcitation in normal-weight and obesity-related hypertension. Hypertension 50: 862-868

34. Huggett RJ, Burns J, Mackintosh AF, Mary DA (2004) Sympathetic neura activation in nondiabetic metabolic syndrome and its further augmentation by hypertension. Hypertension 44: 847-852.

35. Huggett RJ, Scott EM, Gilbey SG, Stoker JB, Mackintosh AF, et al. (2003) Impact of type 2 diabetes mellitus on sympathetic neural mechanisms in hypertension. Circulation 108: 3097-3101.

36. Straznicky NE, Grima MT, Sari Cl, Eikelis N, Lambert EA, et al. (2012) Neuroadrenergic dysfunction along the diabetes continuum: a comparative study in obese metabolic syndrome subjects. Diabetes 61: 2506-2516.

37. Flynn JT (2013) Adiposity, the sympathetic nervous system, and childhood primary hypertension. Hypertension 62: 689-690.

38. Symonds ME (2013) Brown adipose tissue growth and development. Scientifica (Cairo) 2013: 305763

39. Miao Q, Zhang Z, Aaron M C, Ye H, Chong Wee L, et al. (2013) The Prevalence and Predictors of Active Brown Adipose Tissue in Chinese Adults. Eur J Endocrinol.

40. Zhu Z1, Spicer EG2, Gavini CK3, Goudjo-Ako AJ4, Novak CM5, et al. (2014) Enhanced sympathetic activity in mice with brown adipose tissue transplantation (transBATation). Physiol Behav 125: 21-29.

41. Cruickshank JM (2007) Are we misunderstanding beta-blockers. Int J Cardio 120: 10-27.

42. Lim K, Burke SL, Head GA (2013) Obesity-related hypertension and the role of insulin and leptin in high-fat-fed rabbits. Hypertension 61: 628-634.

43. Berrington de Gonzalez A, Hartge P, Cerhan JR, Flint AJ, Hannan L, et al. (2010) Body-mass index and mortality among 1.46 million white adults. N Engl J Med 363: 2211-2219.

44. Zheng W, McLerran DF, Rolland B, Zhang X, Inoue M, et al. (2011) Association between body-mass index and risk of death in more than 1 million Asians. $N$ Engl J Med 364: 719-729.

45. Boggs DA, Rosenberg L, Cozier YC, Wise LA, Coogan PF, et al. (2011) General and abdominal obesity and risk of death among black women. $\mathrm{N}$ Engl $\mathrm{J}$ Med 365: 901-908.

46. Reis JP, Loria CM, Lewis CE, Powell-Wiley TM, Wei GS, et al. (2013) Association between duration of overall and abdominal obesity beginning in young adulthood and coronary artery calcification in middle age. JAMA 310 280-288

47. Romero-Corral A, Montori VM, Somers VK, Korinek J, Thomas RJ, et al. (2006) Association of bodyweight with total mortality and with cardiovascular events in coronary artery disease: a systematic review of cohort studies. Lancet 368 . 666-678.

48. Azimi A, Charlot MG, Torp-Pedersen C, Gislason GH, Køber L, et al. (2013) Moderate overweight is beneficial and severe obesity detrimental for patients with documented atherosclerotic heart disease. Heart 99: 655-660.

49. Coutinho T, Goel K, Corrêa de Sá D, Carter RE, Hodge DO, et al. (2013) Combining body mass index with measures of central obesity in the assessment of mortality in subjects with coronary disease: role of "normal weight central obesity". J Am Coll Cardiol 61: 553-560.

50. Kannel WB, Kannel C, Paffenbarger RS Jr, Cupples LA (1987) Heart rate and cardiovascular mortality: the Framingham Study. Am Heart J 113: 1489-1494.

51. Wilhelmsen L, Berglund G, Elmfeldt D, Tibblin G, Wedel H, et al. (1986) The multifactor primary prevention trial in Göteborg, Sweden. Eur Heart J 7: 279288.

52. Gillman MW, Kannel WB, Belanger A, D'Agostino RB (1993) Influence of heart rate on mortality among persons with hypertension: the Framingham Study. Am Heart J 125: 1148-1154.

53. Heidland UE, Strauer BE (2001) Left ventricular muscle mass and elevated heart rate are associated with coronary plaque disruption. Circulation 104 1477-1482.

54. Leenen FH (1999) Cardiovascular consequences of sympathetic hyperactivity. Can J Cardiol 15 Suppl A: 2A-7A

55. Muller JE, Ludmer PL, Willich SN, Tofler GH, Aylmer G, et al. (1987) Circadian variation in the frequency of sudden cardiac death. Circulation 75: 131-138.

56. Rocco MB, Barry J, Campbell S, Nabel E, Cook EF, et al. (1987) Circadian variation of transient myocardial ischemia in patients with coronary artery disease. Circulation 75: 395-400.

57. Peng YX, Shan J, Qi XY, Zhang SJ, Ma SP, et al. (2006) The catecholaminebeta-adrenoreceptor-cAMP system and prediction of cardiovascular events in hypertension. Clin Exp Pharmacol Physiol 33: 227-231.

58. Livingston EH, Zylke JW (2012) Progress in obesity research: reasons for optimism. JAMA 308: 1162-1164.

59. Mingrone G, Panunzi S, De Gaetano A, Guidone C, laconelli A, et al. (2012) Bariatric surgery versus conventional medical therapy for type 2 diabetes. $N$ Engl J Med 366: 1577-1585.

60. Schauer PR, Kashyap SR, Wolski K, Brethauer SA, Kirwan JP, et al. (2012) Bariatric surgery versus intensive medical therapy in obese patients with diabetes. N Engl J Med 366: 1567-1576.

61. Vest AR, Heneghan HM, Schauer PR, Young JB (2013) Surgical management of obesity and the relationship to cardiovascular disease. Circulation 127: 945-959.

62. Sjöström L, Peltonen M, Jacobson P, Sjöström CD, Karason K, et al. (2012) Bariatric surgery and long-term cardiovascular events. JAMA 307: 56-65.

63. Daugherty SL, Powers JD, Magid DJ, Tavel HM, Masoudi FA, et al. (2012) Incidence and prognosis of resistant hypertension in hypertensive patients. Circulation 125: 1635-1642.

64. Symplicity HTN-2 Investigators, Esler MD, Krum H, Sobotka PA, Schlaich MP, et al. (2010) Renal sympathetic denervation in patients with treatmentresistant hypertension (The Symplicity HTN-2 Trial): a randomised controlled trial. Lancet 376: 1903-1909.

65. [No authors listed] (1998) Tight blood pressure control and risk of macrovascular and microvascular complications in type 2 diabetes: UKPDS 38. UK Prospective Diabetes Study Group. BMJ 317: 703-713.

66. [No authors listed] (1998) Efficacy of atenolol and captopril in reducing risk of macrovascular and microvascular complications in type 2 diabetes: UKPDS 39 UK Prospective Diabetes Study Group. BMJ 317: 713-720.

67. Holman RR, Paul SK, Bethel MA, Neil HA, Matthews DR (2008) Long-term follow-up after tight control of blood pressure in type 2 diabetes. N Engl J Med 359: $1565-1576$

68. Estacio RO, Jeffers BW, Hiatt WR, Biggerstaff SL, Gifford N, et al. (1998) The 
Citation: Cruickshank JM (2014) The Unholy Alliance between Obesity, Type-2 Diabetes, the Sympathetic Nervous System, and Hypertension in Young/Middle-Aged Subjects. J Mol Genet Med S1: 016. doi: 10.4172/1747-0862.S1-016

effect of nisoldipine as compared with enalapril on cardiovascular outcomes in patients with non-insulin-dependent diabetes and hypertension. $\mathrm{N}$ Engl $\mathrm{J}$ Med 338: $645-652$.

69. Fogari R, Zoppi A, Corradi L, Preti P, Malalamani GD, et al. (2000) Effects of different dihydropyridine calcium antagonists on plasma norepinephrine in essential hypertension. J Hypertens 18: 1871-1875.

70. Berl T, Hunsicker LG, Lewis JB, Pfeffer MA, Porush JG, et al. (2003) Cardiovascular outcomes in the Irbesartan Diabetic Nephropathy Trial of patients with type 2 diabetes and overt nephropathy. Ann Intern Med 138: 542-549.

71. Imai E, Chan JC, Ito S, Yamasaki T, Kobayashi F, et al. (2011) Effects of olmesartan on renal and cardiovascular outcomes in type 2 diabetes with overt nephropathy: a multicentre, randomised, placebo-controlled study. Diabetologia 54: 2978-2986.

72. Haller H, Ito S, Izzo JL Jr, Januszewicz A, Katayama S, et al. (2011) Olmesartan for the delay or prevention of microalbuminuria in type 2 diabetes. N Engl J Med 364: 907-917.

73. Heusser K, Vitkovsky J, Raasch W, Schmieder RE, Schobel HP (2003) Elevation of sympathetic activity by eprosartan in young male subjects. Am J Hypertens 16: 658-664

74. Moltzer E, Mattace Raso FU, Karamermer Y, Boersma E, Webb GD, et al (2010) Comparison of Candesartan versus Metoprolol for treatment of systemic hypertension after repaired aortic coarctation. Am J Cardiol 105: 217-222.

75. [No authors listed] (1980) The Australian therapeutic trial in mild hypertension. Report by the Management Committee. Lancet 1: 1261-1267.

76. Medical Research Working Party (1985) MRC trial of treatment of mild hypertension: principle results. BMJ 291: 97-104.

77. Leren P, Helgeland A (1986) Coronary heart disease and treatment of hypertension. Some Oslo Study data. Am J Med 80: 3-6.
78. Menon DV, Arbique D, Wang Z, Adams-Huet B, Auchus RJ, et al. (2009) Differential effects of chlorthalidone versus spironolactone on muscle sympathetic nerve activity in hypertensive patients. J Clin Endocrinol Metab 94: 1361-1366.

79. Zhou WJ, Wang RY, Li Y, Chen DR, Chen EZ, et al. (2013) A randomized controlled study on the effects of bisoprolol and atenolol on sympathetic nervous activity and central aortic pressure in patients with essential hypertension. PLoS One 8: e72102.

80. Deary AJ, Schumann AL, Murfet H, Haydock SF, Foo RS, et al. (2002) Double-blind, placebo-controlled crossover comparison of five classes of antihypertensive drugs. J Hypertens 20: 771-777.

81. Hiltunen TP, Suonsyrjä T, Hannila-Handelberg T, Paavonen KJ, Miettinen HE, et al. (2007) Predictors of antihypertensive drug responses: initial data from a placebo-controlled, randomized, cross-over study with four antihypertensive drugs (The GENRES Study). Am J Hypertens 20: 311-318.

82. Parrinello G, Paterna S, Torres D, Di Pasquale P, Mezzero M, et al. (2009) One-year renal and cardiac effects of bisoprolol versus losartan in recently diagnosed hypertensive patients: a randomized, double-blind study. Clin Drug Investig 29: 591-600.

83. Gosse P, Roudaut R, Herrero G, Dallocchio M (1990) Beta-blockers vs. angiotensin-converting enzyme inhibitors in hypertension: effects on left ventricular hypertrophy. J Cardiovasc Pharmacol 16 Suppl 5: S145-150.

84. Tarnow J, Müller RK (1991) Cardiovascular effect of low-dose epinephrine infusions in relation to the extent of preoperative beta-adrenoceptor blockade. Anesthesiology 74: 1035-1043.

85. Sipahi I, Tuzcu EM, Wolski KE, Nicholls SJ, Schoenhagen P, et al. (2007) Beta-blockers and progression of coronary atherosclerosis: pooled analysis of 4 intravascular ultrasonography trials. Ann Intern Med 147: 10-18.
This article was originally published in a special issue, Molecular \& Cellular Aspects in Obesity \& Diabetes handled by Editor(s). Dr. Masayoshi Yamaguchi, Emory University School of Medicine, USA 